\title{
Performance of silane impregnants for the protection of reinforced concrete
}

\author{
C. Christodoulou
}

AECOM Europe, Colmore Plaza, 20 Colmore Circus Queensway, Birmingham, B4 6AT, UK, email to: Christian.christodoulou@aecom.com

H. Tiplady

Atkins, Chadwick House, Warrington, WA3 6AE, UK

C.I. Goodier \& S.A. Austin

Loughborough University, School of Civil and Building Engineering, Loughborough, UK

ABSTRACT: Silanes can act as hydrophobic pore liners for reinforced concrete (RC) structures. They can significantly reduce the depth of chloride penetration, a major cause of steel reinforcement corrosion. There is little published information however, on their long-term performance. For this study, 32 concrete cores were extracted from eight full-scale RC bridge supporting cross-beams which had been treated with silane 20 years ago. Their rate of water absorption by capillarity was measured and compared with 16 control cores extracted from four non-silane treated RC cross-beams constructed at the same time. Results show that these silanes provide a residual protective effect against water even after 20 years of service.

The performance of silane impregnations on concrete incorporating blended cements, and the effects of different formwork, ages of concrete and curing conditions prior to impregnation were also investigated. Concrete specimens were cast with CEM III/A (Portland cement with 50\% ground granulated blast furnace slag) cement. The performance of the silane impregnation was assessed by the rate of water absorption due to capillary action. The results indicate that improvements in performance were identified within the sample groups of lower w/c ratios, steel finishes, outside curing and double coatings of silane treatment.

The findings from both research programmes indicate that silane impregnations can provide a significant reduction to the water absorption characteristics of both site retrieved and laboratory cast concrete samples. It was observed that performance was reduced with increasing the age of the silane impregnation service life. In addition, silane impregnations applied at specimens with plywood or tampered finish demonstrated a greater reduction on water absorption than specimens with a steel finish.

\section{INTRODUCTION}

Concrete is a naturally porous material. The size and distribution of pores in concrete varies and depends on the constituent materials, quality of compaction, the materials used in the mix design, the water-tocement ratio, the degree of hydration, and curing (Concrete Society 2008). Some of these pores will be interconnected to form a network of pore space that can be penetrated by water, gas or ions.

The relevant transport mechanisms for the ingress of water, gases and ions are (Kropp and Hilsdorf 1995):

- diffusion of free molecules or ions due to a concentration difference;

- permeation of gases or liquids through water saturated specimens due to hydraulic pressure difference; and

- capillary suction of liquids due to surface tension acting in capillaries.
Whilst, these mechanisms act together under natural environmental exposure conditions for atmospherically exposed concrete, capillary suction tends to be the dominant mechanism (Concrete Society 2008, Kropp and Hilsdorf 1995, Ungricht 2004). Ions such as chlorides are transported into the concrete pore system by being dissolved into water, which can subsequently cause corrosion of the steel reinforcement and ultimately spalling of the surrounding concrete cover.

Surface impregnations, such as silanes, are used in various forms in the construction industry to prevent water ingress into concrete structures. Evidence from numerous studies and field applications illustrate that the application of a silane impregnation significantly reduces chloride ingress and therefore corrosion risk of the reinforcement (Basheer et al. 1997, Vries and Polder 1997, Medeiros and Helene 
2008, Calder and McKenzie 2008 Polder and de Vries 2001).

However, there is little or no knowledge regarding their long term performance. The research undertaken by Schueremans et al. (2007) is one of the few studies which investigated their long-term effects on a quay-wall in a port. They showed that the silane was still present after 12 years of exposure in a marine environment and had a residual protective effect on the concrete.

The objective of this study was to address the gap in knowledge with regards to the long-term performance of silane impregnations by undertaking testing of full-scale RC structures and comparing them with data from laboratory cast specimens. Early results of this work have also been reported (Christodoulou et al. 2012, Christodoulou et al. 2013).

\section{METHODOLOGY}

This section presents an overview of the structures from which specimens were extracted, the laboratory programme and the testing procedures.

\subsection{Site specimens}

Figure 1 illustrates a typical sub-structure arrangement of the motorway bridge supporting crossbeams that were examined during this study. Silanes have been applied to a total of 135 similar crossbeams across the UK's Midland Link Motorway Viaducts (MLMV). Of these, 93 cross-beams were located in the viaduct that was chosen for these investigations.

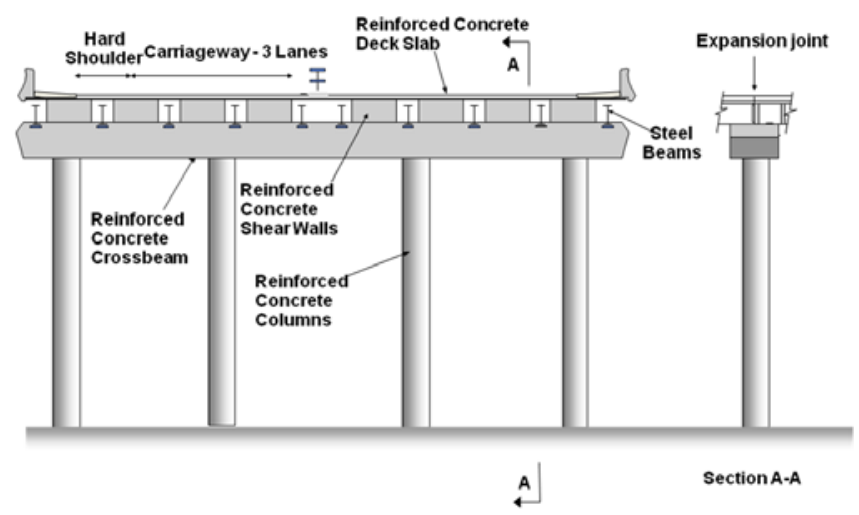

Figure 1. Typical sub-structure arrangement of the UK's Midland Links Motorway Viaducts (MLMV) (Christodoulou et al 2013).

The cross-beams were constructed between 1968 and 1970, although the exact date is not known. Due to the age of the cross-beams, there were no historical records available providing information on concrete mix design such as maximum aggregate size.

Twelve cross-beams were selected, of which eight had previously received a silane treatment 20 years following their construction, whereas the remaining four had not, hence were acting as control specimens (Table 1). The chemical composition of the silane treatment was isobutyl trimethoxy silane. No historical records exist detailing the exact surface preparation procedures, application rates or weather conditions at the time of the application, important factors that can affect silane performance.

Table 1. Age of cross-beams based on an average construction date of 1969 and age of silane treatment at testing (Christodoulou et al 2013b).

\begin{tabular}{|c|c|c|c|c|}
\hline $\begin{array}{l}\text { Cross- } \\
\text { beam } \\
\text { Refer- } \\
\text { ence }\end{array}$ & $\begin{array}{c}\text { Year of } \\
\text { silane } \\
\text { application }\end{array}$ & $\begin{array}{c}\text { Age of } \\
\text { cross-beam } \\
\text { at silane } \\
\text { application } \\
\text { (years) } \\
\end{array}$ & $\begin{array}{c}\text { Age of } \\
\text { silane at } \\
\text { testing } \\
\text { (years) }\end{array}$ & $\begin{array}{l}\text { Age of } \\
\text { cross-beam } \\
\text { at testing } \\
\text { (years) }\end{array}$ \\
\hline A1 & 1991 & 23 & 20 & \multirow{12}{*}{43} \\
\hline B1 & 1993 & \multirow{6}{*}{25} & \multirow{6}{*}{18} & \\
\hline B2 & 1993 & & & \\
\hline B3 & 1993 & & & \\
\hline B4 & 1993 & & & \\
\hline B5 & 1993 & & & \\
\hline B6 & 1993 & & & \\
\hline C1 & 1999 & 31 & 12 & \\
\hline D1 & \multirow{4}{*}{$\begin{array}{c}\text { Control } \\
\text { cross- } \\
\text { beams } \\
\text { (No silane) }\end{array}$} & \multirow{4}{*}{ - } & \multirow{4}{*}{ - } & \\
\hline D2 & & & & \\
\hline D3 & & & & \\
\hline D4 & & & & \\
\hline
\end{tabular}

Four cores (diameter and length of $80 \mathrm{~mm}$ ) were extracted from the top surface of each cross-beam, which represents the most critical area for water ingress. This residual risk can be attributed to the simply supported articulation arrangement with expansion joints above every cross-beam that were known to be susceptible to water leakage. After coring, each core hole was carefully repaired with a shrink-resistance compensating repair mortar.

\subsection{Laboratory specimens}

Laboratory specimens were cast to investigate the influence of different surface finishes, water-tocement ratios (w/c) and cement replacements on the performance of silane impregnations. A CIIIA mix design was used with a $50 \%$ total content of ground granulated blast furnace slag (GGBS) and w/c ratios of $0.3,0.35$ and 0.4 . Furthermore, plywood, steel and hand trowel finishes were also investigated.

Four beams were therefore cast for each mix design with plywood panels inserted between the 1075 $\mathrm{x} 100 \mathrm{x} 100 \mathrm{~mm}$ moulds in order to create the different surface finishes. The concrete was mixed for approximately 2 minutes in a rotary mixer Error! Reference source not found.before placing into the 
moulds and vibrating on a vibration table for between 3-4 minutes to ensure good compaction and the removal of any air voids.

From each beam, 12 cores $(60 \mathrm{~mm}$ diameter and $50 \mathrm{~mm}$ length) were extracted for each type of surface finish examined (Figure 2). The silane impregnation was brush applied at different time intervals in order to also investigate the effect between their performance and age of concrete. In total, 3 different ages were examined, 7 days (single application), 28 days (single application), and $7 \& 28$ days (double application) (Table 2).

The silane impregnation applied was a proprietary water based alkyl alkoxysilane with $20 \%$ solid content by weight.

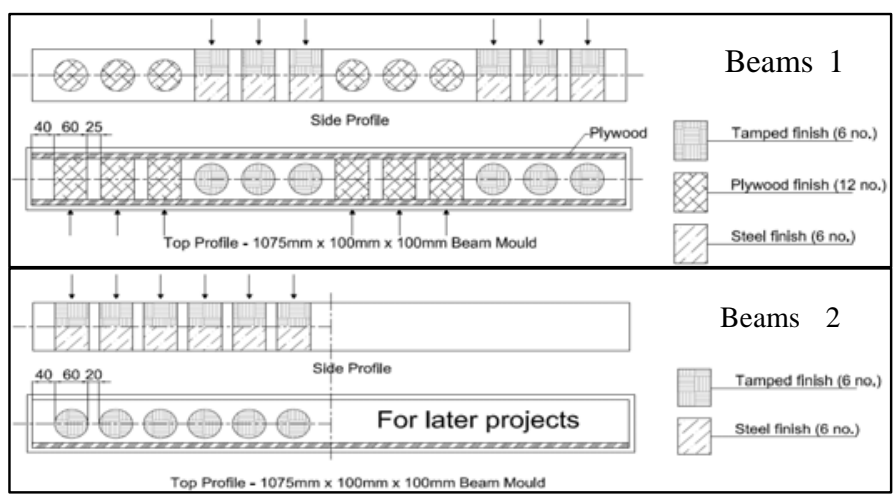

Figure 2. Beam coring layout.

Table 2. Summary of specimens including finish and silane application

\begin{tabular}{|c|c|}
\hline $\begin{array}{l}\text { Tamped Finish: } \\
\text { Total of } 12 \text { cores. }\end{array}$ & $\begin{array}{l}3 \text { cores with silane applied at } 7 \text { days } \\
3 \text { cores with silane applied at } 28 \text { days } \\
3 \text { cores with silane applied at } 7 \text { and } 28 \\
\text { days } \\
3 \text { control cores }\end{array}$ \\
\hline $\begin{array}{l}\text { Steel Finish: } \\
\text { Total of } 12 \text { cores. }\end{array}$ & $\begin{array}{l}3 \text { cores with silane applied at } 7 \text { days } \\
3 \text { cores with silane applied at } 28 \text { days } \\
3 \text { cores with silane applied at } 7 \text { and } 28 \\
\text { days } \\
3 \text { control cores }\end{array}$ \\
\hline $\begin{array}{l}\text { Plywood Finish: } \\
\text { Total of } 12 \text { cores. }\end{array}$ & $\begin{array}{l}3 \text { cores with silane applied at } 7 \text { days } \\
3 \text { cores with silane applied at } 28 \text { days } \\
3 \text { cores with silane applied at } 7 \text { and } 28 \\
\text { days } \\
3 \text { control cores }\end{array}$ \\
\hline
\end{tabular}

\subsection{Testing}

Concrete in contact with a salt solution will become contaminated with chlorides primarily due to capillary absorption rather than diffusion alone. Absorbed chlorides can continue to penetrate by diffusion but at a significantly lower movement rate (Christodoulou et al. 2013). Thus, measuring the rate of absorption (or sorptivity) can provide useful information on the condition of silane treatments. The procedure outlined by BS EN 13057 (British Standards Institution 2002) was employed.

The rate of water absorption can be expressed by equation (1) (Kropp and Hilsdorf 1995). Sorptivity is the uni-axial one-dimensional capillary absorption and can be expressed by equation (2) (British Standards Institution 2002, Kropp and Hilsdorf 1995).

\section{$\underline{\text { Equation } 1}$}

Rate of water absorption $=\frac{W_{w}}{\left(A_{c} \sqrt{t}\right)} \quad \mathrm{kg} / \mathrm{m}^{2} / \mathrm{h}^{0.5}$

Equation 2

Sorptivity $=\frac{V_{w}}{\left(A_{c} \sqrt{t}\right)} \quad m / h^{0.5}$

where $\mathrm{W}_{\mathrm{w}}$ (grams) is the weight gained by the specimen, $A_{c}(\mathrm{~mm} 2)$ the surface area of the specimen in contact with the water, $t$ (seconds) the time of exposure and $V_{w}(\mathrm{~mm} 3)$ the volume of water absorbed.

Measurement of water sorptivity can also be related to the rate of chloride absorption (Medeiros and Helene 2009, Austin and Al-Kindy 2000).

\section{RESULTS}

The results section is divided in two parts, one for results relating to site specimens and the other for the laboratory specimens.

\subsection{Site specimens}

The average cumulative water uptake for each crossbeam's group of specimens over a period of 4 hours of capillary absorption testing is provided in Figure 3 . From this, the rate of absorption can therefore be calculated.

It can be observed that specimens from all crossbeams initially had a high rate of water absorption over the first 15 minutes of testing ( 0.08 hours or 0.29 hours 0.5 ). After this time, for the silane treated cross-beams, in most cases the rate of water absorption was significantly reduced or almost eliminated, indicating steady state conditions. For the control cross-beams, in most cases, the rate of water absorption was reduced but never eliminated.

As such, three distinct rates of water absorption may be derived, i.e. initial between zero and 15 mins, secondary between 15 mins and $4 \mathrm{~h}$ and overall average. It can be observed that control crossbeams D2, D3 and D4 exhibited high rates of water absorption for the initial, secondary and average rates of water absorption. Although all control structures (D1, D2, D3 and D4) initially performed better 
than silane treated cross-beam B6, the later quickly reached near steady state conditions whereas control cross-beams continued their water absorption.

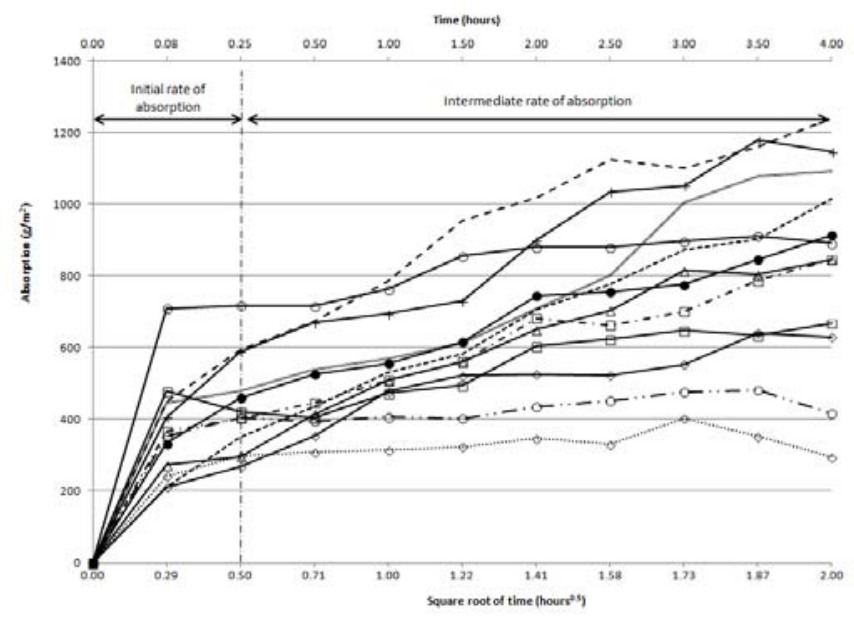

Figure 3. Average cumulative absorption for each crossbeam's group of specimens over 4 hours of capillary absorption testing.

Cross-beam $\mathrm{C} 1$, with the youngest silane treatment at 12 years at time of testing, had a relatively high initial rate of water absorption but quickly reached steady state conditions with overall a very low total cumulative water uptake. Cross-beam B5, with the silane treatment at 18 years at time of testing, was one of the best performing based on initial, secondary and average rates of water absorption and reached near steady state conditions after 15 minutes of testing.

\subsection{Laboratory specimens}

Figure 4 illustrates the cumulative water absorption of laboratory specimens with w/c 0.4 . It can be observed that in all cases, the rate of water absorption of control samples was higher than those of silane treated. This was particularly evident for the specimens with a steel finish. By examining the performance of the control specimens, it can also be observed that the plywood finish resulted in lower rates of water absorption, with the steel finish resulting in the highest.

In addition, in all but one cases it was observed that a double application of a silane impregnation offered significantly lower rates of water absorption. This was not the case for the steel finish, where a double silane application had identical performance to a silane impregnation applied at 7 days.

Figure 5 illustrates the cumulative water absorption of laboratory specimens with w/c 0.35. Again the rate of water absorption of the control samples was in all cases, higher than those of silane treated. However, with this lower w/c ratio there were not significant performance differences in the rate of water absorption for the control specimens with different surface finishes. Interestingly, in this occa- sion, specimens with a steel finish performed slightly better than plywood and tampered finish.
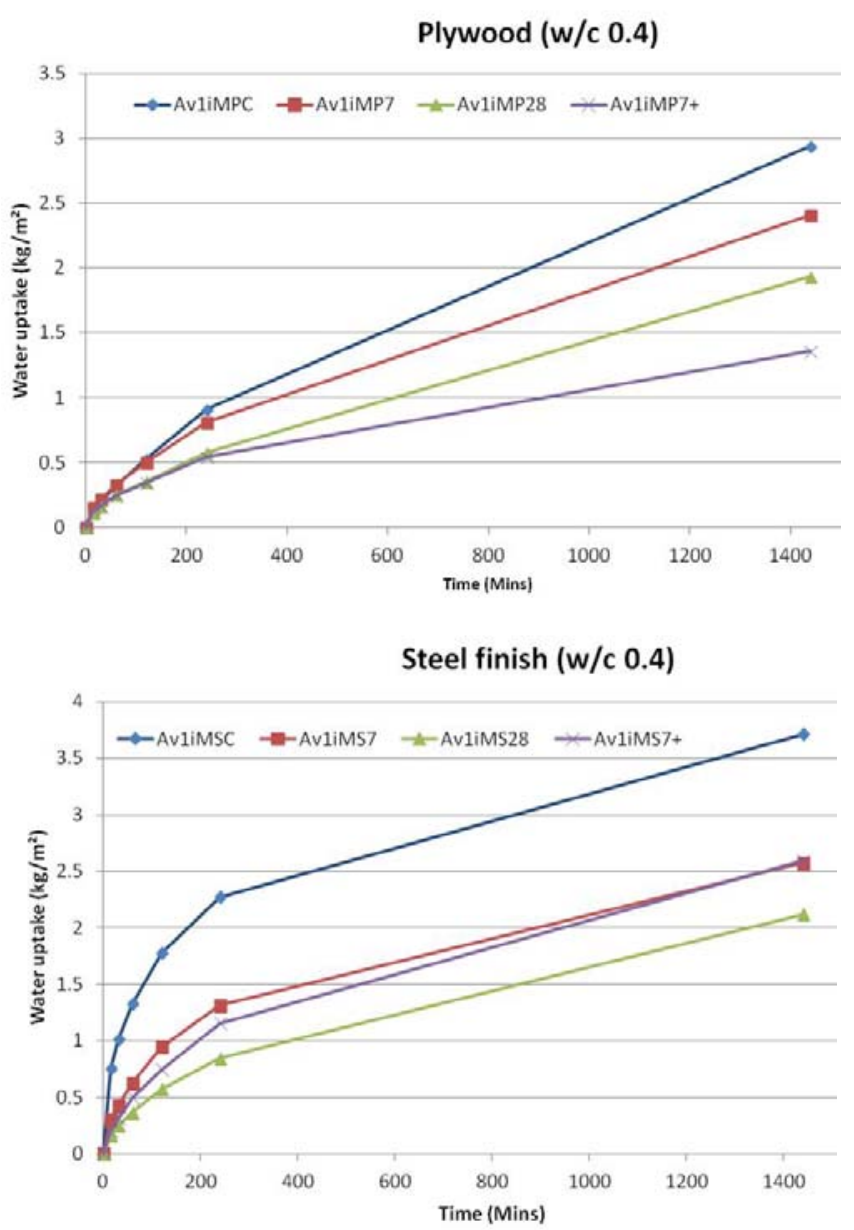

Tamped finish (w/c 0.4)

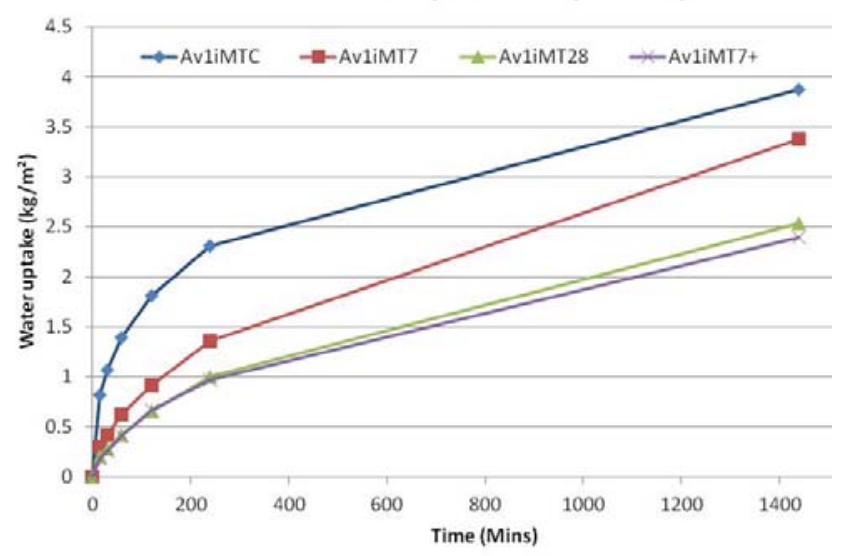

Figure 4. Cumulative absorption for laboratory cured specimens with a w/c 0.4 and different surface finishes (Av1iMTC denotes control specimens, Av1iMT7 denotes silane applied at 7 days, Av1iMT28 denotes silane applied at 28 days and Av1iMT7+ denotes silane applied at 7 and 28 days).

Again in all but one case it was observed that a double application of a silane impregnation offered significantly lower rates of water absorption. This was not the case for the plywood finish, where a 
double silane application resulted in a worse performance than a single application at 7 and 28 days.



Steel finish (w/c 0.35)

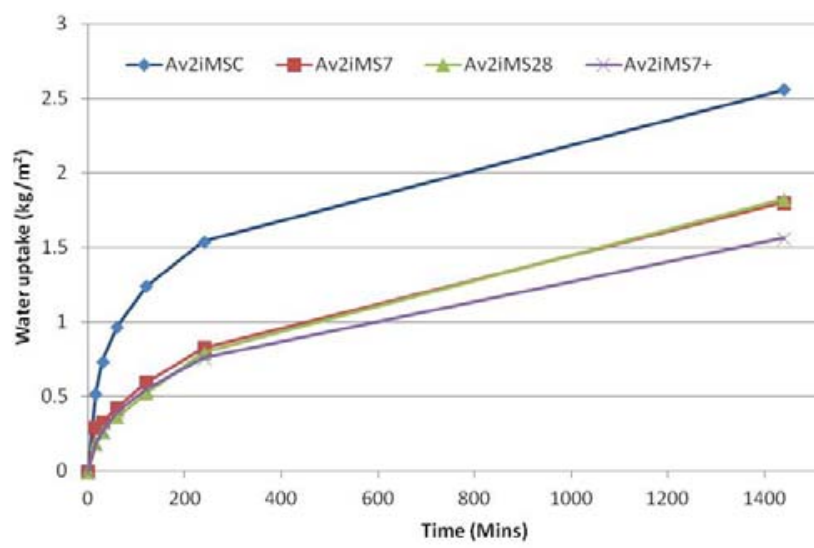

Tamped finish ( $w / c 0.35)$

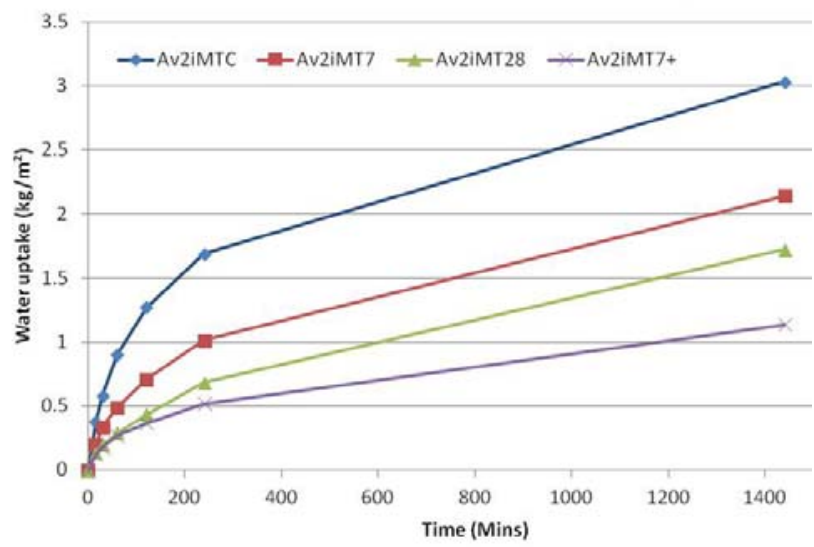

Figure 5. Cumulative absorption for laboratory cured specimens with a w/c 0.35 and different surface finishes (Av1iMTC denotes control specimens, Av1iMT7 denotes silane applied at 7 days, Av1iMT28 denotes silane applied at 28 days and Av1iMT7+ denotes silane applied at 7 and 28 days).

Figure 6 illustrates the cumulative water absorption of laboratory specimens with w/c 0.3 . The rate of water absorption of the control samples was in all cases, higher than those of silane treated. In a similar manner to specimens with a w/c 0.35, a steel finish resulted in lower rates of water absorption for the control specimens.

Interestingly, in all but one case a double application of silane impregnation was generally similar to one application at 28 days. Only in the case of a steel finish, there was a significant reduction by a double application of a silane impregnation. Furthermore, it was also observed that a silane impregnation was significantly more effective with a steel finish.
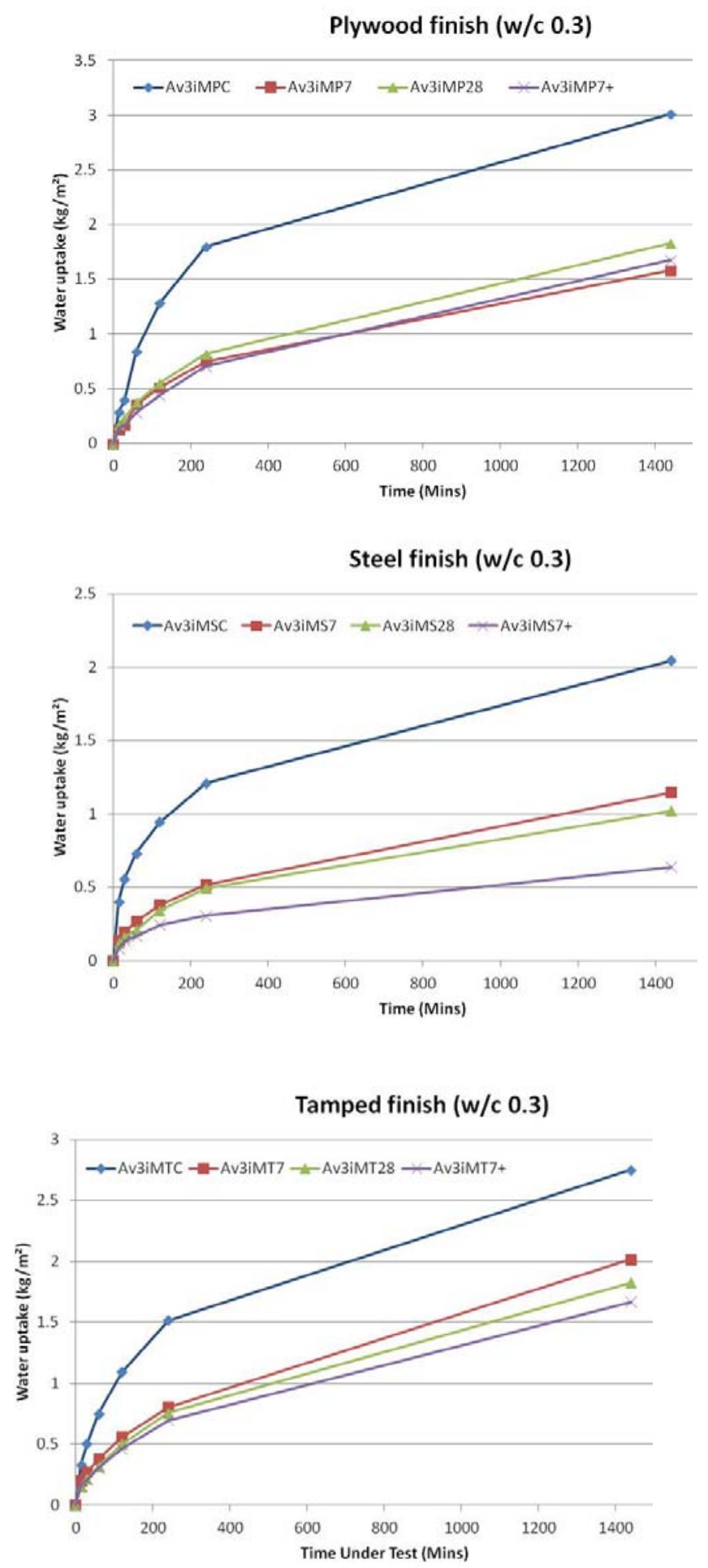
Figure 6. Cumulative absorption for laboratory cured specimens with a w/c 0.30 and different surface finishes (Av1iMTC denotes control specimens, Av1iMT7 denotes silane applied at 7 days, Av1iMT28 denotes silane applied at 28 days and Av1iMT7+ denotes silane applied at 7 and 28 days).

\section{DISCUSSION}

The results suggest that the specimens extracted from silane treated RC structures exhibited a residual protective effect even after 20 years of service life. In particular, specimens from cross-beam C1 which had had the most recent application - outperformed all specimens except those from cross-beam B5. Possible reasons for the difference in performance between specimens of silane treated crossbeams include time dependant effects such as weathering, surface preparation, application rates, environmental conditions at the time of application and differences in the quality of the concrete (Christodoulou et al 2013). Unfortunately, no historical records exist providing these details.

The cumulative water absorption of these extracted specimens (Figure 3) was found to have a fluctuating rate throughout the duration of the test. This is not uncommon, especially when dealing with specimens extracted from full-scale structures (Calder and McKenzie 2008). This variance may be partly explained by changes in the micro-structure of the specimens as water progress from the cover zone (where concrete may be more porous and exhibit surface cracking) towards the core of the specimens. The thickness of this cover zone is affected by quality control on-site and curing conditions. The specimens for this study were extracted from the top of the RC cross-beams an area where concrete is predisposed to bleeding and segregation which can give rise to inconsistencies of the cover zone.

The rate of water absorption of the laboratory-cast control specimens for the 3 different w/c ratios with a plywood finish remained fairly constant. This suggests that a plywood finish allows even hydration at the cover zone area despite varying w/c ratios. In contrast, there was a significant reduction in the rate of water absorption for the steel and tampered finishes when the w/c ratio was reduced. In particular, at a w/c ratio of 0.3 , the steel and tampered finish specimens had a lower absorption that plywood. This reinforces the view that the w/c ratio will have a significant effect, particularly for steel and tampered finishes.

In most cases, the application of a silane impregnation at a concrete age of 7 days, provides a lesser reduction in the rate of water absorption than applications at 28 days. The main exception related to specimens with a steel finish where there was hardly any difference between 7 and 28 days. This reinforces the view, that it is generally preferable to allow at least 28 days of concrete hydration before the application of a silane impregnation.

Furthermore, in all but one case, a double application of silane impregnation at a concrete age of 7 days and again at 28 days again resulted in the highest reduction of rates of water absorption, as would be expected. In practice, this may not always be possible as silane impregnations are primarily applied retrospectively. Nevertheless, a double application can provide improved water absorption characteristics and could be taken under consideration depending upon cost.

Overall, silane impregnations should be considered when determining the corrosion management strategy of a RC structure. Treatments as old as 20 years can still be present and offer a residual protective effect. This is in line with work by Polder and de Vries (2001), Schueremans et al (2007) and Rodum and Lindland (2012). Their presence and effectiveness over time can be evaluated by extracting cores and testing them in the laboratory by capillary absorption testing.

\section{CONCLUSIONS}

Overall, very little published empirical evidence is available which on the durability of silane treatments and their long-term (i.e. 10 years plus) residual protection. Such a gap in knowledge is undesirable given the number, variety and scale of infrastructure treated with hydrophobic treatments such as silanes. From the results of this study, based upon specimens from full-scale RC structures and laboratory cast, the following can be concluded:

- All the treated cross-beams demonstrated that the silane impregnation still provides a residual hydrophobic effect, even with the oldest application from 20 years ago.

- In all but one cross-beam, the most recent silane treated specimens outperformed the older silane treated specimens, suggesting a relationship between degradation of the silane impregnation and duration of environmental exposure.

- Application of silane impregnations after at least 28 days of hardening will result in reduced rates of water absorption as opposed to applications at 7 days only.

- A double application of silane impregnation is usually beneficial and can further reduce the rate of water absorption. This 
effect was more pronounced at higher w/c ratios.

- A plywood finish allows for more even hydration and as a result similar rates of water absorption at varying w/c ratios (0.3, 0.35 and 0.4 ). This suggests that a plywood finish may be preferable for fullscale construction as it provides consistency between casting.

- Steel finishes resulted in greater variations in the rate of water absorption depending on the w/c ratio, especially at values of 0.4 . It is postulated that as the w/c ratio increases, the hydration of concrete may not be even causing variations in the microstructure of the cover zone. This should be taken into consideration when casting large concrete segments with steel formwork.

- Silane impregnations were most effective as the w/c ratio was reduced. This suggests, that the specimens may not have been fully hydrated resulting in a more porous micro-structure allowing greater penetration by the silane impregnation. In particular, the greatest reduction of water absorption was afforded to specimens with a steel finish and a w/c ratio of 0.35 .

\section{REFERENCES}

Austin S.A. and Al-Kindy A.A. 2000, Air permeability versus sorptivity: effects of field curing on cover concrete after one year of field exposure, Mag Concr Res; 52:17-24.

Basheer P.A.M., Basheer L., Cleland D.J., Long A.E.1997, Surface treatments for concrete: assessment methods and reported performance, Const. Build Mat; 11:413-429.

British Standards Institution, BS EN 13057:2002, Products and systems for the protection and repair of concrete structures Test methods - Determination of resistance of capillary absorption, London: BSI; 2002.

Calder A. and McKenzie M. 2008, Performance of impregnants. Published Project Report 362. Transportation Research Laboratory.

Christodoulou C., Goodier C., Austin S., Glass G. Webb J. 2012, Assessing the long-term durability of silanes on reinforced concrete structures, 1st International Congress on Durability of Concrete, Trondheim, Norway; ISBN 978-82-8208031-6. https://dspace.lboro.ac.uk/2134/10925.

Christodoulou C, Goodier C, Austin S, Webb J, Glass G 2013, Long-term performance of surface impregnation of reinforced concrete structures with silane, Construction and Building Materials, 48, pp. 708 - 716 DOI information: 10.1016/j.conbuildmat.2013.07.038,

https://dspace.lboro.ac.uk/2134/13023.

Concrete Society 2008, Technical Report 31, Permeability testing of site concrete. Surrey, UK,.

Kropp J., Hilsdorf H.K. 1995, RILEM Report 12, Performance criteria for concrete durability, Taylor and Francis, Oxford, UK.

Medeiros M.H.F. Helene P. 2008, Efficacy of surface hydrophobic agents in reducing water and chloride ion penetration in concrete, Mater Struct; 41:59-71.

Medeiros M.H.F. Helene P. 2009, Surface treatment of reinforced concrete in marine environment: Influence on chloride diffusion coefficient and capillary water absorption, Const. Build Mat; 23:1476-1484.

Polder R.B. de Vries H. 2001, Prevention of reinforcement corrosion by hydrophobic treatment of concrete, Heron; 46:227238.

Vries J., Polder R.B. 1997, Hydrophobic treatment of concrete, Const. Build Mat; 11:259 -265.

Rodum E. and Lindland J. 2012, Effect of different surface treatment products after 10 years of field exposure, IN: Proceedings of the 1st International Congress on Durability of Concrete, Trondheim, Norway, ISBN 978-82-8208-031-6.

Schueremans L., Gemert D.V. Giessler S. 2007, Chloride penetration in RC-structures in marine environment-Long term assessment of a preventative hydrophobic treatment, Const. Build Mat; 21:1238-1249.

Ungricht H. 2004, Wasserhaushalt und Chlorideintrag in Beton - Einfulls der Exposition und der Betonzusammensetzung, Ph. D. Thesis (In German), Universities of Zurich and Basel. 